УДК $330.342: 338.46$

\title{
ТРАНСФОРМАЦИЯ ОПРЕДЕЛЕНИЯ ПОНЯТИЯ «УСЛУГ» В КОНТЕКСТЕ КОНЦЕПЦИИ ПОСТИНДУСТРИАЛЬНОГО ОБЩЕСТВА
}

\author{
Ю.В. МЕЛЕШКО \\ аспирант кафедры «Экономика и право» \\ Белорусского национального технического университета, г. Минск
}

\begin{abstract}
Аннотация
В статье рассмотрены основные теоретико-методологические подходы к определению понятия «услуга», проблемы классификачии услуг в зависимости от выбранного критерия, а также с учетом метода структурирования общественного производства. Выделены особенности развития сферы услуг в Республике Беларусь в рамках конщепции постиндустриального общества. Сформулирован принциип корреляционной иелесообразности.

Ключевые слова: услуги, классификаџия услуг, структура экономики, постиндустриальное общество.
\end{abstract}

\section{Abstract}

The article describes the main theoretical and methodological approaches to the definition of "service", the problems of classification of services, depending on the selected criterion, as well as taking into account the method of structuring of social production. The features of the development of services within the concept of post-industrial society are highlighted.The principle of the correlation of expediency is formulated.

Keywords: services, classification of services, structure of economy, post-industrial society.

\section{ВВЕДЕНИЕ}

Одной из наиболее ярких тенденций экономики конца XX - начала XXI веков является высокий темп развития сферы услуг. Промышленное производство - основа успешного экономического развития стран, начиная с конца XVIII века, - уступило место сфере услуг, в связи с чем происходит структурная перестройка мировой экономики, сопоставимой по масштабам с индустриальной революцией. Сегодня уровень развития сферы услуг стал критерием социально-экономического развития государства. Так, «страна не может быть причислена к развитым странам мира, если в ее сфере услуг создается меньше 60\% ВНП» [4].

Доминирование сферы услуг в структуре общественного производства имеют широкие последствия не только в экономике, но и в социальной сфере, является одним из признаков перехода к постиндустриальной стадии развития общества. Концепция постиндустриального общества появилась в 50-60-х гг. ХХ в. Этот период называют эпохой тотальной индустриализации, когда главной движущей силой перехода цивилизации в качественно новое состояние выступала научно-техническая революция. Наиболее полную концепцию постиндустриального общества представил в своей работе «Грядущее постиндустриальное общество» в 1973 г. Д. Белл. По мнению автора, «понятие постиндустриального общества является аналитической конструкцией, а не картиной специфического или конкретного общества. Она есть некая парадигма, социальная схема, выявляющая новые оси социальной организации и стратификации в развитом западном обществе», и далее: «Постиндустриальное общество... является «идеальным типом», построением, составленным социальным аналитиком на основе различных изменений в обществе» [22, с.120]. 
А. Белл выделял три типа обществ: доиндустриальное, индустриальное и постиндустриальное, отличия между которыми кроется в типах производства. Доиндустриальное общество основано на «взаимодействии с природой», соответственно центральную роль в экономике занимает добывающая промышленность, а производительность труда крайне мала. Индустриальное общество - «взаимодействие с преобразованной природой», суть которого сводится к использованию человеком машины для преобразования естественной окружающей среды в техническую. Постиндустриальное общество основано на «игре между людьми», в которой на фоне машинной технологии поднимается технология интеллектуальная, основанная на информации [22, с. 157].

Несмотря на то, что исторически производство услуг существовало всегда, за последние пятьдесят лет произошло кардинальное изменение роли услуг в структуре народного хозяйства. Начало бурного развития сферы услуг связано с технологическим прогрессом в области информатизации и коммуникации, резким увеличением производительности труда, изменением структуры занятости населения в пользу сферы услуг, повышением доходов домашних хозяйств и, соответственно, их затрат на услуги. Развиваясь как отрасль обслуживания аграрной и производственной сферы, со временем сфера услуг заняла господствующее место в структуре общественного производства: ресурсы всех отраслей экономики в той или иной мере проходят через сферу услуг, приобретая дополнительную добавленную стоимость.

В научный оборот термин «услуга» впервые был введен французским экономистом Ж.-Б. Сэем в 1803 г. в работе «Трактат по политической экономии» [3]. По мнению автора, в процессе производства создаются не материальные блага, а услуги, даже отношения между рабочим и капиталистом рассматриваются как обмен услугами. Идея видения взаимоотношений между трудом и капиталом как «обмен услугами» была поддержана и развита в дальнейшем другим французским экономистом - Ф. Бастиа, который под услугой понимал «не только реальную затрату труда в процессе производства, но и всякое усилие вообще, которое прилагается кем-либо или от которого освобождается тот, кто данной услугой пользуется» [4, с. 60]. Несмотря на ведущую роль сферы услуг в процессе общественного производства, до сегодняшнего дня нет единого методологического подхода к определению понятия «услуги», их места и роли в экономике, что не позволяет в полной мере выработать стратегию управления современной экономикой.

\section{РЕЗУЛЬТАТЫ И ИХ ОБСУЖДЕНИЯ}

\section{Изменение роли сферы услуг в структуре общественного производства}

Производство является базовым понятием экономических дисциплин традиционного типа, под которым понимают «производство средств к жизни, необходимых для удовлетворения потребностей (материальных, духовных) [7]. Одновременно с модернизацией производственно-технологических отношений происходят и изменения в структуре общественного производства. Как уже было упомянуто, на протяжении многих лет локомотивом экономики практически любого развитого государства было промышленное производство, что является отличительной чертой индустриального общество. В это время общественное производство подразделялось на материальную и нематериальную составляющую: в отраслях материального производства создается материально-вещественный продукт, а нематериального - нематериальные блага и услуги. Широкое распространение получает термин «непроизводственная сфера», под которой понималась «совокупность отраслей народного хозяйства, удовлетворяющих разнообразные, кроме производства материальных благ, потребности людей и общества в целом» [8]. 
К непроизводственной сфере, как правило, относили жилищно-коммунальное и бытовое обслуживание населения, пассажирский транспорт, связь, здравоохранение, физическую культуру и социальное обслуживание, просвещение, культуру, искусство, науку и научное обслуживание, управление. В состав материального сектора производства включали широкое многообразие производственных отраслей, а также отрасли сельского хозяйства. Основным критерием отнесения к материальному или нематериальному сектору производства служило материальное овеществление результатов труда, в том числе и преобразование природы с целью приспособления ее к человеческим потребностям. Непосредственно к услугам относились только те услуги, потребителями которых являлись домашние хозяйства. Деловые услуги не входили в нематериальный сектор производства и не были выделены в самостоятельную сферу, однако это не означало их отсутствия. Услуги, направленные на обслуживание производственного и сельскохозяйственного процессов, являлись составной частью производства, и, соответственно, учитывались в сфере материального производства.

Выделение нематериального характера результата труда в качестве критерия отнесения той или иной деятельности к нематериальному производству привело к появлению подхода к определению понятия «услуга» путем противопоставления материальной продукции. Этот подход и сегодня используемый рядом современных ученых. Так, например, по мнению Г. Ассэль, услуги представляют собой «неосязаемые блага, которые приобретаются потребителями, но не связаны с собственностью» [5, с. 337]. Ф. Котлер считает, что «услуга - любая деятельность, которую одна сторона может предложить другой; неосязаемое действие, не приводящее к владению чем-либо» [6, с. 541]. При таком подходе на первый план выходит такое свойство услуги как неосязаемость. Услуги нематериальны и невидимы, и, как следствие, не подразумевает передачу прав собственности на объект. Неосязаемость услуги порождает невозможность ее хранения, что сказывается на специфике рынка услуг: зачастую возникает проблема согласования спроса и предложения. В связи со своим нематериальным характером услуга также зачастую обладает ненасыщаемостью. Несмотря на противопоставление услуг продуктам материального производства, эти понятия не являются антиподами. Услуга, как и физический продукт, представляют собой товар - «продукт труда, произведенного для продажи» [7, с. 833]. Следовательно, услуга в результате ее потребления способна удовлетворять потребности людей и имеет свою потребительную стоимость.

Разделение общественного производства на два сектора - материальный и нематериальный, - по мере развития и усложнения мировой экономики уже в первой трети $\mathrm{XX}$ века начинает утрачивать свою актуальность. Оно не способно отразить как изменения, происходящие в материальном секторе (изменение соотношения сельского хозяйства, добывающей и обрабатывающей промышленности), так и место и роль нематериальной сферы. В связи с этим возникает потребность в разработке нового подхода к структурированию общественного производства.

К. Кларком и Ж. Фурастье в 40-х годах XX века была предложена трехсекторная модель общественного производства, в соответствии с которой к первичному сектору относится сельское хозяйство и добывающая промышленность, вторичному - обрабатывающие отрасли, третичный - сфера услуг. Согласно их взглядам. «... в общественном производстве выделяется триада секторов. Переход от одного сектора к другому осуществим благодаря, во-первых, экономическому развитию, приводящему к относительным изменениям в спросе на продукцию секторов, во-вторых, росту производительности, отображающемуся на относительном изменении спроса на трудовой ресурс в разных секторах. Со временем доминантным становится третичный сектор - как с точки зрения занятых в совокупности занятости, так и с позиции удельного веса продукции данного сектора в ВВП» [17, с. 36]. 
Деление экономики на три сектора соответствовало реалиям хозяйственной жизни первой половины XX века, так как сфера услуг по своей роли в экономике уже выделилась в самостоятельные сектор. и все три сектора экономики имели такое существенное значение в общественном производстве как по числу занятых в них, так и по доле в создании общественного богатства, что исключить тот или иной сектор или объединить по каким-либо критериям представлялось нецелесообразным.

Выделение услуг в самостоятельный сектор, получивший название «сфера услуг», наравне с сельскохозяйственным и производственным секторами приводит к необходимости поиска иной отличительной характеристики, нежели материальность или нематериальность продуктов производства. Мо мнению ряда экономистов, такой отличительной чертой является понимание услуги как экономически целесообразной деятельности, процесса. Р. Шелп предложил считать услугой любую производственную деятельность, за исключением сельского хозяйства, добычи полезных ископаемых и промышленности $[10$, с. 6]. Хотя еще К. Маркс утверждал, что услуга означает «не что иное, как ту особую потребительную стоимость, которую доставляет этот труд, подобно всякому другому товару, но особая потребительная стоимость этого товара получила специфическое название «услуга» потому, что труд оказывает услуги не в качестве вещи, а в качестве деятельности» [8, с. 413]. Услуги - «действия, направленные непосредственно на потребителя» [9, с. 400]. При оказании услуги не создаются самостоятельные продукты или материальные ценности, под услугой понимается некая полезная деятельность, готовность и способность к осуществлению действия, при этом упор следует сделать на полезности такого действия. Понимание услуги как деятельности предполагает неотделимость услуги от источника и взаимодействие производителя и потребителя услуги. Услугу как действие также определяет и Л. Берри: «товар представляет собой объект, устройство, вещь, тогда как услуга - это действие, исполнение, усиление» $[10$, с. 6]. В процессе оказания услуги потребитель принимает участие (непосредственно либо дискретно - во время заказа и приемки), что обуславливает интерактивный характер услуг. Кроме того, производство и потребление услуги, как правило, совпадает во времени и в пространстве, хотя последнее претерпевает изменения в связи с развитие информационных технологий.

Расширив описанный выше подход к определению услуги, в качестве основной отличительной черты услуги можно выделить результат оказываемой деятельности, а именно - изменение состояния объекта, на которого была направлена услуга. По мнению Т. Хилла, товар - «это физический объект, который может быть присвоен, а, следовательно, и передан от одной хозяйственной единицы к другой» $[10$, с. 6]. Услугой же является «изменение состояния человека или предмета, принадлежащего любому участнику экономических отношений, которое достигается в результате сознательных действий другого участника данных отношений. При этом воздействие происходит на основе их предварительной добровольной договоренности» [11]. Добрынин А.И. и Журавлева Г.П. определяют услугу как «целесообразную деятельность человека, результат которой имеет полезный эффект, удовлетворяющий какие-либо потребности человека» $[12$, с. 52]. Из данных определений следует, что услуга, чаще всего, имеет адресный характер. В сравнении с результатом материального производства - предметом, - услуга более индивидуальна, так как предполагает прямой контакт с потребителем. Учитывая специфику процесса оказания услуги (кто, где и когда ее предоставляет), а также субъективные факторы восприятия услуги (в зависимости от личных характеристик потребителя), следует выделить еще одну специфическую характеристику услуги - непостоянство качества услуг.

Изначально, сектор услуг, хоть и являлся самостоятельным, однако использовался, в основном, для обслуживания сельского хозяйства и промышленности и удовле- 
творения потребностей населения. Это подтверждается тем, что традиционными отраслями сферы услуг являются торговля и транспорт. Однако начиная с 60-70 гг. XX века в экономически развитых странах в виду бурного роста сферы услуг, связанного с технологическим прогрессом в области информатизации и коммуникации, начала увеличиваться диспропорция между названными секторами. Резкое увеличение производительности труда привело к изменению структуры занятости населения в пользу сферы услуг. Со временем сфера услуг заняла господствующее место в структуре общественного производства: ресурсы всех отраслей экономики в той или иной мере проходят через сферу услуг, приобретая дополнительную добавленную стоимость. В.Л. Иноземцев в своей работе «Современное постиндустриальное общество: природа, противоречия, перспективы» приводит следующие данные: «если в 1900 году соотношение американцев, производящих материальные блага и услуги, оценивалось как 63:37, то девяносто лет спустя - уже как 22:78» [18, с. 60].

Максимальное проникновение сферы услуг в торговлю через менеджмент и маркетинг привело к тому, что реализация материального товара напрямую потребителю стало практически невозможным (невыгодным) [2]. Уже не сфера услуг обслуживает реальные производственно-хозяйственные процессы, а наоборот. Сфера услуг выступает потребителем ресурсов всех отраслей народного хозяйства.

Довольно резкое изменение соотношения производственного сектора и сферы услуг, усложнение и разнообразность третичного сектора привело к необходимости пересмотра методологического подхода к структуре общественного производства в части детализации третичного сектора. Так, Д. Белл в 70-х гг. прошлого века наряду с указанными тремя секторами экономики выделил еще два - четвертичный и пятеричный. К третичному сектору автор отнес транспорт и коммунальные услуги, к четвертичному торговля, финансы, страхование и операции с недвижимостью. Здравоохранение, образование, отдых, научные исследования, государственные услуги составляют пятеричный сектор [19, с. 117]. Именно с развитием четвертичного и пятеричного секторов экономики ученый и связывал переход общества к постиндустриальной стадии развития.

Несмотря на несомненные достоинства подхода к структурированию общественного производства Д. Белла, как то: отображение сложности и неоднородности услуг, соответствие (в большей степени по сравнению с использующимся до этого трехсекторальным подходом) современным экономическим реалиям, характеризующимся расширением и диверсификацией сферы услуг, по справедливому мнению В.Л. Иноземцева, недостатком является отсутствие «методологического принципа, позволяющего обнаружить ... основные грани, вокруг которых могло бы быть построено принципиальное деление всего общественного производства» [20, с. 63]. Это и явилось причиной ограниченности применения такого подхода при дальнейшем количественном увеличении и качественном разнообразии отраслей, относящихся к сфере услуг: новые услуги становятся все более сложными и тесно переплетающимися с производством, чаще всего услугу сложно выделить как самостоятельный продукт. Возникает сложность в вопросе отнесения определенного действия к сфере услуг как в общем, так и к третичному, четвертичному или пятеричному секторам - в частности.

В.Л. Иноземцев предложил иной подход к структурированию общественного производства - двухполюсную систему. С одной стороны - отрасли, тяготеющие к субъектно-объектному виду взаимодействия, с другой - к субъектно-субъектному. Субъектно-объектный полюс представляет взаимодействие человека с предметом своей деятельности. В эту группу включаются все отрасли первичного сектора, ряд отраслей вторичного сектора (металлургия, химическая промышленность, машиностроение), а также такие отрасли экономики, традиционно относящиеся к третичному сектору, как транспорт и коммунальное хозяйство. Критерием отнесения указанных отраслей к субъектно-объектному полюсу послужили повторяемость производственных процес- 
сов, воспроизводимость их результата, высокие показатели выработки в стоимостном выражении на одного работника и отрицательный или колеблющийся около нуля темп роста занятости. Субъектно-субъектный полюс включает в себя такие отрасли, в которых взаимодействие людей основано на межперсональном общении, продукт данных отраслей отличается низкой степенью воспроизводимости и представлен в значительной мере информацией и знаниями. К этому полюсу можно причислить сферу культуры и развлечений, образование, научные исследования, информационные, финансовые, страховые, юридические и консультационные услуги, операции с фондами и недвижимостью, а также государственное управление [20, с. 66].

Описанный выше подход В.Л. Иноземцева позволяет избежать проблемы определения доли материальной составляющей в услуге, и соответственно, отнесения определенного товара к материальному производству или к сфере услуг. Однако использование такого подхода осложняется активным развитием услуг массового потребления.

Определение понятия «услуга», основные черты услуг и их классификация

Проанализировав исторический аспект развития понятия «услуга», учитывая ее качественное и количественное разнообразие и высокие темпы развития, предлагаем следующее определение:

Услуга - это основанная на межсубъектных отношениях целесообразная деятельность, направленная на удовлетворение потребностей производства и домашних хозяйств.

Как уже было отмечено выше, к основным характерным чертам услуги относятся: неосязаемость, недолговечность, невозможность хранения, отсутствие передачи прав собственности, неотделимость от источника, совпадение производства и потребления во времени, непостоянство качества, интерактивный характер. В процессе развития рынка сферы услуг и расширения качественной дифференциации оказываемых услуг, рассмотренные определения и соответствующие характеристики услуг приобретают все более относительный характер. Действия, которые можно назвать услугами, многочисленны и разнообразны, как и объекты, на которые направлены эти действия, в связи с чем всегда можно будет найти услугу, которая не соответствует какому-либо параметру из любого определения. Так, к примеру, знания, полученные человеком в результате обучения, сохраняются и после оказания услуги в области образования. Поэтому в последнее время специалисты сосредоточили свое внимание на видах деятельности, которые можно было бы отнести к сфере услуг, их классификации.

Существует множество классификаций услуг в зависимости от выбранного критериального признака. По функциональному подходу услуги классифицируются на производственные и потребительские, то есть услуги, удовлетворяющие потребности производства и услуги, потребляемые домашними хозяйствами (индивидами). Исторически потребительские услуги более изучены и, чаще всего, интуитивно понятны, в общем смысле это услуги, предоставляемые населению в области культуры, искусства, здравоохранения, бытового обслуживания. Производственные услуги более сложные, они являются источниками повышения эффективности производства и являются стратегическими для современной экономики [4, с. 73]. В зарубежной литературе распространено деление услуг на корпоративные и SOHO (smalloffice, homeoffice). Корпоративные услуги отличаются технологичностью и, соответственно, высокой стоимостью, к ним, в первую очередь, относятся деловые услуги. К сегменту услуг SOHO причисляют услуги, предоставляемые частным предпринимателям, руководителям и индивидуальным потребителям [14, с. 79].

Дж. Зингельман расширил функциональный подход, предложив выделить наряду с производственными и потребительскими услугами социальные и распределительные. По мнению данного автора к производственным услугам следует отнести инжиниринг, консалтинг, финансовые и банковские услуги, страхование, к потребительским - ресто- 
ранные, гостиничные, бытовые, домашние услуги. Социальные услуги включают в себя такие услуги, как образовательные, медицинские, благотворительные, а распределительные - торговые, транспортные, связь, фрахт [15].

К. Лаврок в зависимости от объекта оказания услуг выделяет 4 группы услуг:

- услуги, направленные на человека (медицинские, спортивные, ресторанные);

- услуги, направленные на сознание человека (информационные, образовательные, культурные);

- услуги, направленные на физические объекты (транспортные, грузовые, торговые);

- услуги, направленные на нематериальные активы, основанные на обработке информации (банковские, финансовые, страховые) [16].

В зависимости от места в производственном процессе услуги могут классифицироваться на конечные и промежуточные, кроме того на микроэкономическом уровне выделяют также и внутрипроизводственные услуги, которые производятся и потребляются внутри хозяйствующего субъекта. Такая классификация услуг имеет значение при количественной оценке созданного ВВП - промежуточные услуги, как правило, не учитываются в данном показателе.

Наиболее часто встречающейся классификацией услуг является разделение услуг на материальные и нематериальные. Нематериальные услуги - чистые услуги, - услуги с максимальной степенью неосязаемости, например услуги юристов, артистов, учителей [4, с. 77]. Услуги, создающие новую потребительскую стоимость или восстанавливающие ранее потребленную, относятся к материальным услугам. В качестве примера можно привести ремонт и пошив одежды, автосервис. При этом выделяют услуги с разной степенью взаимозаменяемости и связи с товарами:

- услуги, заключенные в товар (кинокартины, аудиозаписи),

- услуги, дополняющие торговлю товарами (банковские, риэлтерские, логистические),

- услуги, являющие заменителем при продаже товара (ремонт, лизинг),

- услуги, не связанные с реализацией товаров (юридические, медицинские) [1].

Услуги и товар (материальные продукты) находятся в динамическом взаимодействии. Услуги оказываются не только в сфере нематериального производства, но и материального. Услуги пронизывают все отрасли экономики, в связи с чем достаточно сложно провести четкую границу сферы услуг. В одном случае услуги могут выступать в качестве основного вида деятельности, в других - обязательно присутствуют в материальном производственном процессе, занимая, однако, меньший ареал, так как в современной экономике растет доля производства продукции с учетом требований и пожеланий конкретного заказчика - потребителя. Таким образом, граница между материальной и нематериальной составляющей услуги подвижна, практически все производственные процессы начинают в большей или менышей степени тяготеть к услуговым.

Вопрос классификации той или иной услуги, отнесении ее к определенному сектору экономики имеет принципиальное значение при статистическом учете. Существует несколько подходов к описанию структуры сектора услуг, используемых разными странами и международными организациями. По методике Международного валютного фонда, применяемой для ведения учета международной торговли услугами в платежных балансах стран мира, выделяются 11 видов услуг, подразделяемых на коммерческие и государственные: транспортные; поездки (деловые поездки, культурный туризм, обучение или лечение за рубежом); услуги связи; строительные; страховые; финансовые; роялти и лицензии (платежи и доходы по нефинансовым активам и права собственности, например патенты, копирайт, торговая марка); другие деловые услуги (торговля, услуги по операционному лизингу, профессиональные и технические услуги, НИОКР); персональные, культурные и рекреационные; государственные (операции правительственных учреждений с товарами и услугами, которые оно совершают с резидентами той страны, в которой они размещены). 
В соответствии с Генеральным соглашением по торговле услугами услуги подразделяются на 12 групп: деловые услуги; связь; строительство и связанные с ним инженерные услуги; торговля; образование; услуги, связанные с окружающей средой; финансовые; по охране здоровья и социальные услуги; туризм и услуги, относящиеся к поездкам; рекреационные, культурные и спортивные; транспортные; другие услуги.

Еще одной распространенной классификацией услуг является разделение услуг по критерию предложения, описанной в международной стандартной отраслевой классификации. К сфере услуг относят следующие отрасли:

- оптовая и розничная торговля, ремонт;

- гостиницы и рестораны;

- транспорт, складское хозяйство и связь;

- финансы;

- операции с недвижимостью, аренда и предоставление деловых услуг;

- государственное управление и обеспечение военной безопасности, обязательное социальное обеспечение;

- образование;

- здравоохранение и социальная работа;

- прочие коммунальные, социальные и персональные услуги;

- частное домохозяйство с наемным обслуживанием;

- экстерриториальные организации и учреждения [14, с. 79-80].

В Республике Беларусь официальной статистикой используется следующая классификация сферы услуг:

- торговля, ремонт автомобилей, бытовых изделий и предметов личного пользования;

- гостиницы и рестораны;

- транспорт и связь;

- финансовая деятельность;

- операции с недвижимым имуществом, аренда и предоставление услуг потребителям;

- государственное управление;

- образование;

- здравоохранение и предоставление социальных услуг;

- предоставление коммунальных, социальных и персональных услуг [21].

В основу классификации отраслей, относящихся к сфере услуг в Республике Беларусь, легла Международная стандартная отраслевая классификация с некоторыми поправками на современные национальные социально-экономические особенности: в Беларуси не распространены частные домашние хозяйства с наемным обслуживанием. Примечательным является то, что в соответствии с Международной стандартной отраслевой классификацией, а также и в белорусском статистическом учете в отличие от классификаций, используемых МВФ и ВТО, строительство относится к промышленному производству, так как в результате этой деятельности создается материальновещественный продукт, собственность на который передается заказчику.

\section{Особенности становления постиндустриального общества в Республике Беларусь}

В первом полугодии 2014 г. в структуре ВВП Республики Беларусь сфера услуг заняла 48,1 \% [29]. Наиболее весомыми в сфере услуг являются секция «Торговля, ремонт автомобилей, бытовых изделий и предметов личного пользования», секция «Транспорт и связь» и секция «Операции с недвижимым имуществом, аренда и предоставление услуг потребителям», доля которых в структуре валовой добавленной стоимости сферы услуг составляет соответственно 30,8, 18,4 и 12,7 \% [29]. Как видим из 
приведенных данных, на сегодняшний день в сфере услуг ведущие позиции занимают традиционные виды услуг, - торговля, транспорт и связь, то есть услуги, обслуживающие реальный сектор экономики.

В современной экономике практически все отрасли материального производства становятся все более «услугооказывающими» как внутренне (лица, занятые в промышленности, не принимают непосредственное участие в производственном процессе), так и внешне (создание сети сервисных служб, центров работы с клиентами). Тем не менее, как уже было отмечено выше, увеличение доли услуг в структуре ВВП и занятости не означает деиндустриализацию производства. Чрезмерное диспропорциональное развитие услуг, в частности финансовых, неизбежно приведет к экономическому краху. Примером может служить мировой экономический кризис 2008 года.

Рассматривая взаимосвязь сфер общественного производства, следует учитывать фактор времени: «в «текущем масштабе времени» «непроизводственная» сфера зависит от функционирования материального производства (в том числе и в силу вторичности доходов), а в «долгосрочном масштабе» - развитие материального производства, его структура, эффективность во многом детерминированы масштабами и качеством функционирования сферы услуг (состоянием науки, образования, здравоохранения и т.д.» [4, с. 40].

В постиндустриальном обществе рост сферы услуг осуществляется на фоне роста высокотехнологичных и наукоемких отраслей, базирующихся на новейших достижениях научно-технического прогресса. Технико-технологические усложнения производственного процесса повысили спрос бизнеса на широкий круг услуг, способствующих повышению его конкурентоспособности. В результате последствий глобализации и информационной революции преимущества товаров в современной экономике формируются, как правило, не на основе соотношения цена-качество, а на широком использовании восокотехнологичных инноваций во всех отраслях и сферах мирового хозяйства, позволяющих, с одной стороны, существенно сократить транзакционные издержки на всех стадиях воспроизводственного процесса - от НИОКР до реализации товара, - и с другой стороны, создать товар уникального качества.

В связи с изложенным выше, дальнейшее развития сферы услуг в Беларуси целесообразно осуществлять с учетом количественного и качественного развития сферы материального производства. Необходимо выработать принцип корреляционной целесообразности: развитие сферы услуг детерминировано развитием сферы материального производства, и в первую очередь, его наукоемкими отраслями.

Рост удельного веса сферы услуг осуществляется на фоне роста высокотехнологичных и наукоемких отраслей, базирующихся на новейших достижениях научнотехнического прогресса. Технико-технологические усложнения производственного процесса повысили спрос бизнеса на широкий круг услуг, способствующих повышению его конкурентоспособности. Решающим фактором повышения конкурентоспособности национальной экономики в постиндустриальном обществе становится активное развитие и разностороннее применение фундаментальных знаний, при этом знания становятся не только средством производства, но и продуктом (товаром). Превращение науки в массовую специальность, дифференциация и интеграция наук, расширение фронта проводимых комплексных и междисциплинарных исследований привели к небывалому росту знания и еще гораздо большему росту потока информации в обществе во всех сферах [26].

Изобретение микропроцессорных технологий и персонального компьютера в 80-х годах XX века стали революцией в информационных технологиях. С этого времени на микропроцессорах и интегральных схемах создаются компьютеры, компьютерные сети, системы передачи данных (информационные коммуникации). Средства преобразования информации стали электронными, произошла миниатюризация всех узлов, устройств, приборов, машин, создаются программно-управляемые устройства и процессы. Ис- 
пользование указанных инноваций в сфере информационных технологий имеет большое влияние на социально-экономическое развитие общества. В зависимости от количества, качества накопленной информации, способы ее накопления, обработки, передачи и распространения приводят к формированию определенного типа общественных отношений, в том числе и экономических. При взаимодействии информации и общества происходит изменение социальных регуляторов, в том числе морали, а также структурное изменение всего общества. Благодаря повсеместному широкому внедрению информации в производство и жизнь повышается мобильность и емкость рынка, усиливается конкуренция за право собственности на информацию. Роль собственности на информацию и ее материальные носители резко возросла в последние годы, что приводит к появлению новых форм социальной дифференциации.

По сравнению с индустриальным обществом, система экономических отношений в постиндустриальном обществе представляется более сложной. Изучая проблему классов и классовой борьбы в постиндустриальном обществе, С.Ю. Солодовников отметил, что это связано «во-первых, с увеличением количества периферийных социальноэкономических укладов; ускорением трансформации доминирующих укладов; усилением профессионально-квалификационного расслоения общества; затрудняется перемена труда между различными квалификационно-профессиональными группами, между индивидами, занятыми в информационной и традиционной экономиках, и т.д.; во-вторых, с повышенной динамикой постиндустриальной экономической системы и ростом доли сектора услуг в создании и распределении общественного богатства; в-третьих, с тем, что сегодня создана самая совершенная в истории человечества система идеологического «зомбирования» (НЛП) в постиндустриальных и индустриальных странах, препятствующая осознанию большинством населения своих классовых интересов» [27, с. 89].

В связи с усложнением производственного процесса появляется необходимость в подготовке высококвалифицированных специалистов. Постоянно растут инвестиции в человеческий капитал, расходы на образование и здравоохранение. Повышение доли сферы услуг в структуре экономики значительно повлияло на рынок труда и образования: наблюдается тенденция интеллектуализации труда, появляются новые формы занятости, такие как: работа неполный день, применение аутсорсиснга, дистанционная работа. Сфера услуг заключает в себе значительный потенциал общественного развития, так как дает возможность повышения квалификации, самообразования, свободное время для занятия спортом, для отдыха и туризма, что в свою очередь стимулирует развитие индустрии досуга и изменение в структуре и качестве услуг, предоставляемых домашним хозяйствам. Таким образом, для постиндустриального общества характерен переход от «производства вещей» к «производству людей» с повышением доли сферы услуг в общественном производстве.

\section{ВЫВОДЫ}

Сегодня произошло не только изменение места услуг в современной экономике, но также подверглось трансформации и традиционное представление об услугах. Если в индустриальном обществе услуги играли подчиненную роль, то в постиндустриальном услугам отведено доминирующее положение. При этом наблюдается бурный рост не только по количественным характеристикам. Сегодня услуги имеют широкую качественную дифференциацию. Д. Белл отмечал, что «слово „услуга“ не должна вызывать вводящих в заблуждение образов быстрого приготовления еды и низкооплачиваемых работников; основными являются финансовые, профессиональные и конструкторские услуги, здравоохранение, образование и социальная сфера, и лишь на последнем месте этой шкалы стоят бытовые услуги» [18, с. 55]. Все чаще под услугами подразумевают 
современные отрасли, использующие новейшие информационные технологии, происходит сокращение доли традиционных услуг, как-то транспорт, торговля, государственные услуги, возникают новые услуги - компьютерные услуги, информационные сети, электронная торговля.

В постиндустриальной экономике сфера услуг становится доминирующим фактором экономического развития. Именно она «задает основные параметры, формирует систему внутренних и внешних пропорций для данной экономической системы, определяет структуру экономики, взаимосвязь между различными отраслями и видами деятельности» [25, с. 3]. Третичный сектор экономики базируется на индустриальном, включающем в себя как материальное, так и нематериальное производство, как уже отмечалось ранее, они настолько тесно взаимозависимы и активно воздействуют друг на друга, что зачастую сложно провести четкую границу между ними.

Существует несколько подходов к определению услуги: 1) как противопоставление товару, 2) услуга как целесообразная деятельность, 3) услуга как полезный эффект деятельности, удовлетворяющей потребности. В рамках этих подходов выделяются такие основные характерные черты услуги, как неосязаемость, недолговечность, невозможность хранения, отсутствие передачи прав собственности, неотделимость от источника, совпадение производства и потребления во времени, непостоянство качества. Однако на наш взгляд, в качестве ключевой характеристики услуги следует выделить субъект-субектный характер: то есть процесс оказание услуги основывается на взаимоотношении потребителя услуги и ее производителя.

В контексте становления постиндустриального общества дальнейшее развитие сферы услуг в Республике Беларусь целесообразно осуществлять в соответствии с государственной концепцией социально-экономическим развития, учитывая особенности развития материального производства.

\section{ЛИТЕРАТУРА}

1. Макаревич А.Н. Предпосылки становления и экономические особенности функционирования сферы услуг / А.Н. Макаревич // Вестник Новгородского государственного университета. - 2010. - №60. - С. 8-12.

2. Ушаков, Д.С. Сфера услуг в развитии постиндустриальных экономических систем / Д.С. Ушаков. - Ростов н/Д, 2002.

3. Сэй, Ж.-Б. Трактат по политической экономии / Жан-Батист Сэй. Экономические софизмы; Экономические гармонии / Фредерик Бастиа; [сост., вступ. ст. и коммент. М. К. Бункиной и А. М. Семенова]. - М. : Дело : Акад. нар. хоз-ва при правительстве Рос. Федерации, 2000.

4. Бурменко, Т.Г. Сфера услуг в современном обществе: экономика, менеджмент, маркетинг: учеб. пособие / Т.Г. Бурменко, Н.Н. Даниленко, Т.А. Туренко. - М.: КноРус, 2015.

5. Ассаэль, Г. Маркетинг: принципы и стратегия: Учебник для вузов / Г. Ассаэль. - М.: ИНФРА-М, 2001.

6. Котлер Ф. Маркетинг менеджмента/ Ф. Котлер. - СПб.: Питер Ком., 1998.

7. Большой энциклопедический словарь: философия, социология, религия, эзотеризм, политэкономия / Главн. научн. Ред. и сост. С.Ю. Солодовников. - Мн. МФЦП, 2002.

8. Маркс К., Энгельс Ф. Соч. 2-е изд. Т.26, Ч.1.

9. Долан, Э. ДЖ. Экономикс: Англо-русский словарь-справочник / Э. ДЖ. Долан, Б.И, Домненко. - М.: Лазурь, 1994.

10. Почекина, В.В. Услуги в международной экономике / В.В. Почекина, Ю.П. Якубук. - Минск: БИП-С, 2003. 
11. Hill T. On goods \& services // Rev. of income \& wealth. - W., 1977. - Ser. 23. №4. - P.315-338.

12. Добрынин, А.И. Общая экономическая теория / А.И. Добрынин, Г.П. Журавлева. - СПб.: Изд-во «Питер», 2000.

13. Румянцева, Е.Е. Новая экономическая энциклопедия / Е. Е. Румянцева. - М.: ИНФРА-М, 2005.

14. Стрелкова, И.А. Мировая экономика: учеб. пособие / И.А. Стрелкова - М.: РИОР: ИНФРА, 2014.

15. Singelmann J. From agriculture to Service: The transformation of Industrial Employment. - Beverly Hills., 1978.

16. Лавлок, К. Маркетинг услуг: персонал, технология, стратегия / К. Лавлок, 4-е изд.: Пер. с англ. - М.: Издательский дом «Вильямс», 2005.

17. Вередюк О.В. Детерминанты занятости в концепции постиндустриального общества / О.В. Вередюк // Вестн., СПбГУ. Сер.5: Экономика. - СПб.: Изд-во СПбГУ, 2010. - № 4. - С.35-42.

18. Иноземцев, В.Л, Современное постиндустриальное общество: природа, противоречия, перспективы / В.Л. Иноземцев. - М.: Логос, 2000.

19. Bell Daniel/ The Coming of Post-Industrial Society:A Venture in Social Forecasting/New York, Basic Books, 1973.

20. Иноземцев В.Л. Структурирование общественного производства в системе постиндустриальных координат (методолого-теоретические аспекты) / В.Л. Иноземцев // Российский экономический журнал. - 1997. - № 11-12.

21. Сфера услуг в Республике Беларусь: статистический сборник. - Мн., 2012.

22. Белл Д. Грядущее постиндустриальное общество. Опыт социального прогнозирования / Д. Белл; пер. с англ.; изд. 2-ое, испр. И доп. - М.: Academia, 2004. - CLXX, 788 c.

23. Ушаков, Д.С. Сфера услуг в развитии постиндустриальных экономических систем / Д.С. Ушаков. - Ростов н/Д, 2002. - 27 с.

24. Айрих И.В. Природа и специфика услуг / И.В. Айрих // Теория и практика общественного развития. - 2014. - №10. - С. 148-153.

25. Махошева, С. А. Сфера услуг и формирование новой архитектуры развития региональных социально-экономических систем / С.А. Махошева. - Нальчик, 2009. - 50 с.

26. Гохберг Л. Национальная инновационная система России в условиях «новой экономики» / Л. Гохберг // [Электронный ресурс]. - Портал «Инновации, инвестиции, индустрия». - М., 2003. - Режим доступа: // http://www.3i.ru/problems.asp?ob_no=1235, свободный. - Загл. с экрана. - Дата доступа: 26.01.2015

27. Солодовников С.Ю. Гносеологические трудности при изучении классов в постиндустриальном обществе / С.Ю. Солодовников// Социологический альманах. 2012. - № 3. - С. 74-91.

28. Большая Советская Энциклопедия (В 30 томах). Гл. ред. А.М. Прохоров. Изд. 3-е, М.; Советская Энциклопедия, 1974. Т.17. Морошин-Никши. 1974. 616 с. (с. 499).

29. Худякова И.В. Сфера услуг / Экономический бюллетень НИЭИ Министерства экономики Республики Беларусь. - 2014. - №8. - С. 37-41.

Статья поступила в редакциию 7 сентября 2015 года. 